\title{
PSICANÁLISE E CIÊNCIA
}

Roberto Calazans

Doutor em Teoria Psicanalítica pelo Programa de Pósgraduação em Teoria Psicanalítica da UFRJ; professor adjunto do Departamento das Psicologias da Universidade Federal de São João Del Rei (MG).
RESUMO: Apresentam-se as razões pelas quais tanto o pensamento científico quanto o pensamento psicanalítico recusam o realismo em todos os seus matizes para pensar o que estrutura uma experiência. Desta análise, extrai-se como conseqüência a irredutibilidade de qualquer tratamento do sujeito por meio de um processo de objetivação, demarcando assim o campo de atuação próprio aos problemas pensados e tratados pela psicanálise. Tira-se também como conseqüência que esta irredutibilidade da psicanálise a uma objetivação não torna a psicanálise incompatível com o mundo científico, ao contrário, esta disjunção se dá exatamente pela compatibilidade lógica entre o pensamento psicanalítico e o pensamento científico.

Palavras-chave: Sujeito, psicanálise, realismo.

ABSTRACT: Psychoanalysis and science. This article shows the reasons through which the scientific thought as well as the psychoanaIytic thought deny the realism in all its basis in order to think what structures an experience. The irreductability of any treatment of the subject through the means of an objective process is extracted from this analysis by the author; therefore, drawing the field of the problems which are thought and treated by psychoanalysis. Furthermore, this objective psychoanalytic process doesn't make psychoanalysis incompatible with the scientific world; in fact, this disjunction just happens through the logics between the psychoanalytic thought and the scientific thought.

Keywords: Subject, Psychoanalysis, realism.

Dretendemos demonstrar que há compatibilidade lógica entre o pensamento científico e o pensamento psicanalítico. Para tal, partiremos da crítica ao realismo científico, ou meIhor, do que Bachelard chama de 'função realista': a tentativa de situar algo que seja indubitável - seja ele uma realidade ou um pensamento. 
Demonstraremos que um pensamento científico efetivo se torna fecundo quando abandona as pretensões de buscar uma realidade e passa a estabelecer 0 processo de objetivação. Ou seja, quando abandona o naturalismo de uma realidade e volta sua atenção para a artificialização sem qualidades que caracteriza o pensamento científico. E quea psicanálise, a partir dos desdobramentos efetuados por Lacan em sua retomada da obra freudiana, abandona o realismo ao considerar que seu problema é de ordem ética por estar às voltas com um sujeito, sujeito esse definido não como instância fundamental, mas como um efeito do semsentido de um mundo afetado pela existência da ciência.

A função realista, quando estamos às voltas com o pensamento científico, nós a podemos encontrar tanto em um indutivismo ingênuo ${ }^{1}$ quanto no positivismo lógico. ${ }^{2}$ Poderíamos dizer em linhas gerais que ambos postulam que há uma realidade independente de qualquer operação de pensamento, da qual só nos restaria descobrir suas leis de funcionamento - indutivismo ingênuo - ou encontrar uma maneira mais adequada de comunicar al go sobre ela - teoria da linguagem do positivismo lógico. Entretanto, esse realismo em momento algum se questiona sobre o sentido ambíguo que o termo realidade pode apresentar.

Partamos então da definição da realidade, colocando um dos pressupostos de um pensamento real ista: uma realidade se desenvolve necessariamente no tempo e no espaço. Ora, para um realista, o tempo e o espaço seriam dados de nossa experiência. Basta um pouco de pensamento filosófico para demonstrar a insuficiência de tal pressuposto realista.

Como coloca Kant, o tempo e o espaço são condições de uma intuição. Por serem condições, não podem ser parte da realidade que é condicionada, isto é, em função de espaço e tempo serem condições sinequa non da experiência, não podem ser dados na experiência. Tanto que Kant denomina o estudo das condições a priori

\footnotetext{
${ }^{1}$ Segundo Chalmers, um indutivista ingênuo postula que o "crescimento da ciência é contínuo, para a frente e para o al to, conforme o fundo de observação aumenta" (1999, p.26). Esse fundo de observações dos fatos é que possi bilitaria afirmar proposições e derivar leis e teorias verdadei ras. "A fonte da verdade não é a lógica, mas a experiência" (1999, p.31) . 0 fim último dessa perspectiva é a possibilidade de fazer previsões sobre a experiência vindoura. Ainda de acordo com Chalmers, o indutivista ingênuo é aquele que quer transformar certa visão popular da ciência em sua imagem, ou seja, é relativo ao que Bachelard chamaria de "senso comum".

2 Pasquinelli (1983, p.20), ao citar Carnap escrevendo sua autobiografia intelectual, destaca uma passagem em que este aponta a importância de Moritz Schlick, que teria antecipado e influenciado o movimento do Círculo deViena. Eum dos aspectos considerados como centrais é "a interpretação da verdade como coordenação unívoca de um enunciado com um fato". Além desses autores podemos consi derar outros, ligados ao positivismo lógico, como A.J. Ayger, G. Ryle e C.W. Morris.
} 
da experiência de "estética transcendental" , 3 que seria o estudo do surgimento de uma intuição sob determinadas condições que são independentes da experiência.

M esmo que Kant recuse o realismo, ele, por outro lado, comete um equívoco e recai sob o conceito de função realista de Bachelard: ${ }^{4}$ estipula que toda experiência só pode se desenvolver no tempo eno espaço tal como pensados pela física de Newton e pela geometria euclidiana. Essa condição sine qua non da experiência seria o espaço tridimensional e o tempo como coordenadas da intuição a priori. Os dois seriam tomados então como absolutos. Desse modo, ao situar uma condição de possibilidade da experiência, Kant os considera imutáveis e pretenderá aval iar todo conhecimento possível que deve se desenrolar nessas condições geométricas do tempo e do espaço. Ou seja, mesmo que não sejam realidades no sentido estrito, desempenham a mesma função de indubitabilidade.

Entretanto, hoje nós temos uma concepção do espaço riemanniano, topológico, que traz como conseqüência dúvidas sobre a conceituação da geometria euclidiana. O espaço riemanniano aparece tanto em função de impasses da geometria euclidiana quanto em função de produção de realidades que não existiam antes. Desse modo, temos, em vez de uma realidade dada ou de condições indubitáveis, um processo de objetivação que produz tanto novos fenômenos quanto novos problemas e teorias.

Mas o realista poderia responder que ainda assim essas objetivações são abstrações e que toda ciência sempre parte de uma realidade que é dada. Pouco importa então se não há mais uma consideração do tempo como uma função da geometria: a teoria muda, a real idade ficaria. Entretanto, seria pertinente colocar em questão o que seria essa realidade. De saída, podemos conceber duas definições distintas de realidade: ou como um dado, ou como resultado do processo de objetivação. Para demonstrar a inanidade desse modo de definir a realidade, façamos al guns questionamentos.

Partamos de um ponto simples: se a realidade é algo que nos é dado, éimportante então perguntar como ele é dado. De uma maneira geral responde-se que ele é dado por afetar um aparelho sensorial.

Entretanto, encontramos duas maneiras de afetar um aparelho sensorial que não se justapõem: algo pode afetar um aparelho sensorial de maneira física ou de maneira biológica. Fisicamente, temos apenas uma variação de intensidade desprovida de qualidades (variações de intensidade de luminosidade, por exemplo). Biologicamente, algo só afeta um organismo se fizer parte de seu meio biológi-

\footnotetext{
3 "Denomino etética transcendental uma ciência de todos os princípios da sensibilidade a priori" (KANT, 1980, p.40).

4 "Toda filosofia, explícita ou tacitamente, com constância ou sub-repticiamente, se serve de uma função realista. Toda filosofia projeta ou supõe uma real idade" (BACHELARD, 1990, p.141).
} 
co; a onda sonora existe no meio físico, mas dependendo de sua intensidade ela pode ou não afetar um organismo. Um exemplo do que estamos levantando nos é fornecido por Canguilhem (1992). Um carrapato, após o acasalamento, pode ficar 18 anos imóvel se o único excitante que o fará se movimentar estiver presente no meio, ou seja, o odor de manteiga rançosa que emana das glândulas cutâneas do animal. Apenas esse excitante pode fazer o carrapato se movimentar para sugar o sangue que irá dar continuidade ao processo de reprodução, desenvolvendo os ovos que ficaram encapsulados até então. E quando falamos em processo de reprodução, estamos às voltas com um processo biológico que não responde só aos estímulos físicos do ambiente. ${ }^{5}$

Ora, dessa maneira, vemos que se falarmos de aparelho sensorial, devemos, de saída, considerar se estamos falando de um organismo ou de uma relação apenas física. U ma relação mecânica não leva a uma afetação própria ao organismo, mas somente a uma de suas partes. E quando consideramos o organismo, devemos situá-lo em função de como a biologia situa um organismo. Segundo François Jacob (1983), o organismo éa realização de um programa genético. Sua finalidade é a de manter-se vivo para a transmissão dos caracteres da espécie. Em outros termos, com o surgimento da genética, o organismo passa a ser considerado apenas como uma modalidade de sustentar a reprodução. E esta não tem finalidade alguma, é uma finalidade nela mesma. E, como sustenta Jacob, um programa genético ao qual o organismo está submetido "não recebe lições da experiência" (1983, p.13). Assim, ao colocarmos a questão do que significa'ser afetado' por uma realidade, por uma experiência, não encontramos uma univocidade dos termos: esse sintagma não é algo óbvio.

Mas poderíamos interrogar sobre o sentido de realidade de outra maneira. Esta, conforme veremos, também não tem um sentido unívoco. Pois em um primeiro sentido, a realidade é tomada também como um dado. Mas aqui, um dado seria definido, de acordo com Robert Blanché (1935), como algo que se apresenta sem qualquer operação de pensamento, sem que eu possa inferir alguma coisa sobre ele. Sei apenas o que é, sem saber explicar como. Uma experiência pura, ou os elementos da experiência.

Ora, como encontrar algo definido desse modo sem uma operação de pensa mento? Ao tentar encontrar esses dados brutos, desprovidos de qual quer operação de pensamento, temos que, de maneira necessária, introduzir uma operação de pensamento. Um bom exemplo desse procedimento nos é ofertado pela química:

\footnotetext{
5 “Nota-se que, durante um tempo considerável, 0 animal pode ficar totalmente indiferente, insensível a todas as excitações que emanam de um meio como a floresta e que a única excitação capaz de desencadear seu movimento, excluindo qualquer outra, é o odor de manteiga rançosa" (CANGUILHEM, 1992, p.146).
} 
ao tentar separar os compostos, eu devo, em primeiro lugar, saber qual reagente específico devo introduzir para ter o elemento que desejo; e devo, em segundo lugar, acrescentar um dado que não estava inserido antes. Para realizar tal obra, devo estabelecer uma relação entre os dados. E somente estabelecendo essa relação posso chegar ao que seria um dado. Mas este aparece em função de uma operação de pensamento. Queira guiar-se pelo o olhar e encontrará apenas um mau pensamento. Um exemplo de Lacan: um menino recebe um tapa e pergunta se foi uma violência ou um carinho. Dependendo da resposta, ele chora ou fica encantado (LACAN, 1955-1956/ 1985a, p.15), ou seja, o sentido não está no tapa.

Mas realidade pode ter também outro sentido: em vez de chamarmos de dado, que sempre se apresenta a mim e por isso pode ser considerado subjetivo, chamamos de 'realidade' o objeto que é independente de minha sensação. A terra, em nossa experiência, é aparentemente imóvel, mas, na realidade, gira em torno de si. Ora, como chegamos a esse saber de uma organização que ultrapassa a nossa experiência? Por meio da mediação que o pensamento estabelece. E ele estabelece a relação entre os dados. É em função dessa relação calculada que 0 pensamento determina cada dado - ou variável - em função dos outros dados. Só o pensamento é capaz de estabel ecer relações entre os dados para constituir os fatos. Um fato é obra do pensamento. ${ }^{6}$

Por essa razão, podemos afirmar que não encontramos o dado puro, pois não há como abrir mão do pensamento para atingi-lo: um dado só é um dado em um sistema específico de pensamento que o considera como tal. Do mesmo modo que não encontramos uma realidade inteiramente organizada, pois isto suporia uma articulação completa de todos os dados. Ora, um dado só é um dado em uma problemática específica, que estabelece relações específicas. Assim, não faz mais sentido falar em uma experiência/ realidade inteiramente organizada da qual se ignoraria apenas a lei de funcionamento. 0 estabelecimento da lei e a realização é um único e mesmo movimento da atividade científica. Desse modo, encontramo-nos sempre situados diante de uma série que organiza os fatos. Daí a necessidade de pensar a série. E pensar a série é percorrer todo seu esforço de realização experimental. Um fato, portanto, será sempre um tecido de afirmações que deve, como indica Bachelard (1996, p.76), "incorporar as condições de aplicação de um conceito no próprio sentido do conceito". Essa realização experimental denomina-se, de acordo com Jean U IImo (1967, p.27), 'definição operatória': “a descrição de um processo regular para

\footnotetext{
6 "Deste modo, a realização leva a melhor sobre a realidade. Esta primazia da realização desclassifica a realidade. U m físico só conhece verdadeiramente uma realidade quando a realizou, quando deste modo é o senhor do eterno recomeço das coisas e quando constitui nele um retorno eterno da razão" (BACHELARD, 1979, p.21).
} 
referir, medir, mais geralmente atingir e identificar o conceito definido". Essa definição comporta o postulado da repetição, ou seja: a definição, por produzir um real, abre mão de um sujeito. A sua precisão se comporta justamente nesta condição: a de que, seja quem for, possa repetir e atingir os mesmos resultados definidos de modo operacional, desde que esteja atento a qual problema está tratando.

Chegamos assim ao ponto que nos interessa: toda vez que considero um pensamento que produz um real a partir da integração em uma rede conceitual daquilo que a própria rede considera como dados - as variáveis - e quando caracterizo esse pensamento como sendo um pensamento desprovido de qualidades, eu só posso referi-lo a uma espécie de problemas: os problemas objetivos, nas quais não encontro qualquer consideração sobre um valor. Afinal de contas, o que seria um valor senão dotar de importância algo, alguém, ou mesmo uma idéia?

Ora, uma idéia valorizada é uma idéia que al guém supõe mais importante do que as outras. Desse modo, como abrir mão dessa idéia? Por essa razão, não podemos deixar de considerar que o pensamento abandona os problemas em que se encontram valores. Um exemplo maior é o de Einstein: 0 abandono, na física, da mecânica newtoniana se faz em função dos impasses dessa teoria; e quando se adota a teoria da rel atividade, esta se faz a partir do estabelecimento de uma nova articulação conceitual que passa a promover tanto o que é considerado objetivo como o que é considerado critério de avaliação da objetividade física.

Ora, a partir do momento em que podemos pensar que uma teoria pode ser ultrapassada em função de uma nova articulação conceitual, nada nos impede de pensar que os impasses da nova teoria levarão à ultrapassagem da teoria nova. Um pensamento científico é sempre provisório. Dessa feita, quando Einstein reclama que não pode haver uma teoria quântica, é em função de querer que a sua teoria seja a mais importante, saindo, desse modo, do pensamento científico. Einstein é o caso do conceito da máxima citada por Bachelard (1996, p.19): “os grandes homens são úteis à ciência na primeira metade de sua vida e nocivos na outra metade". Retomando: quando há um valor envolvido, há a questão de que algo é, ao menos em um primeiro momento, insubstituível.

Não há, portanto, uma realidade que possa ser considerada em si, nem como um dado, nem como uma organização misteriosa cuja lei de funcionamento nos escapa; desse modo, a realidade perde as qualidades e passa a ser situada como variáveis. 0 pensamento perde suas amarras e pode se colocar sob a marca de um infinito: ao diversificar e precisar as relações, eu posso, de maneira infinita, produzir novos fenômenos - e novos problemas - que não estavam previstos antes.

Devemos, então, tomar por conseqüência não só a possibilidade de pensar uma realidade mediada por um sistema de pensamento, mas também a inanidade 
de tentar buscar a realidade de um pensamento. Um pensamento, conforme apontamos antes, não pode ser considerado uma passividade que seria ora um dado, ora o resultado de uma operação. 0 pensamento não pode ser um dado: pois se este é suposto pelo pensamento, como poderia o pensamento ora supor, ora ser suposto? 0 pensamento não pode ser uma realidade objetiva: pois esta é justamente o resultado da operação do pensamento. Logo, o pensamento éa condição de produção de um real, e abandona de vez o registro de uma realidade que se impusesse por si só.

Podemos, então, definir que a recusa do realismo - ou melhor, da função realista - e de seus pressupostos - o estudo de uma real idade dada ou a instauração de um princípio de pensamento que seja indubitável - tem por princípio a afirmação de que, em uma atividade científica, os dados são organizados em função do sentido do problema, o que pressupõe a perda de qualidade tanto dos objetos de pesquisa quanto das teorias que dão sustentação de afirmação de existência desses objetos. $E$ as conseqüências disso é a assunção do infinito uma vez que a ciência se define pelo artifício - e a impossibilidade de tentar tratar um pensamento como se fosse uma realidade. Ao contrário: o pensamento, como condição de realização, retira do mundo qualquer pretensão de realidade autônoma. E a diversificação dessas condições retira qualquer pretensão de um princípio de organização que seja indubitável.

Isso posto, podemos colocar como fica a questão do sujeito em psicanálise? Como podemos dar consistência ao tratamento dessa questão? Em primeiro lugar, não podemos esquecer o aforismo de Lacan: "o fato de a psicanálise haver nascido da ciência é patente. Que pudesse ter surgido de outro campo, é inconcebível" (LACAN, 1966/ 1998, p.232). Isso significa que antes do aparecimento da ciência, de seu modo de fabricação de problemas e de objetividades, não seria possível pensar em psicanálise. Daí Milner (1996, p.120) afirmar quea psicanáliseé síncrona com a ciência: ela é logicamente compatível com a atividade científica. Essa compatibilidade lógica leva a psicanálise a abandonar o realismo, a buscar uma realidade para tratar de um sujeito. Afinal, se a atividade científica se caracteriza por uma produção de redes de conceito estabelecido pelo pensamento, a psicanálise não poderia recorrer à tentativa de tratar um pensamento como se fosse uma realidade. É esta a tese inaugural de Freud: a de que há pensamentos inconscientes. E a razão de Lacan, em seu retorno a Freud, valorizar a função e o campo da linguagem:

\footnotetext{
"Afirmamos, quanto a nós, que a técnica não pode ser compreendida nem corretamente aplicada, portanto, quando se desconhecem os conceitos que a fundamentam. Nossa tarefa será demonstrar que esses conceitos só adquirem pleno sentido ao se orientarem no campo da linguagem e se ordenarem na função da fala." (LACAN, 1953/ 1998, p.247)
} 
Todo o encaminhamento anterior nos permite afirmar que a recusa do realismo no pensamento científico se dá em função das conseqüências da atividade científica, a saber: valorização do artifício em detrimento do natural e retirada de qualidades do pensamento. A psicanálise, por ser logicamente compatível com a atividade científica, também será partidária do artifício - em que não podemos afirmar que al guma coisa seja dada - e do pensamento sem qualidades - que impede a consideração de um princípio indubitável. Eis a razão de a psicanálise tratar do sujeito como um efeito da fal ta de qualidades que afeta um mundo em que a atividade científica é possível. 0 sujeito é uma resposta frente à perda de qualidade tanto do mundo quanto do pensamento. E nessa demanda de uma qualidade - ou de uma resposta que sirva de ponto de parada para o sujeito apresentam-se apenas soluções parciais, fruto de um resíduo: não el iminável que introduz aqui também a função do infinito.

Nessa seqüência de compatibilidades, podemos traçar mais uma: a psicanálise irá, assim como a ciência, considerar os dados que ela recebe em função de um problema específico. Isto é: irá considerar o sujeito em função do problema que ele indica, a saber, o problema ético. ${ }^{7} \mathrm{Um}$ problema se torna ético quando não posso deixar de responder a ele, mesmo que não haja solução alguma dada ou evidente sobre ele. Desse modo temos uma distinção entre dois registros de problemas: um em que é possível traçar um encaminhamento objetivo e traçar uma definição operatória; outro, em que estão em jogo 0 sujeito e a questão da val idade de suas decisões. A psicanálise, por ser logicamente compatível com a atividade científica, não irá apenas recusar o realismo, mas irá também afirmar a especificidade de seu campo de ação e abandonar a pretensão de ser uma ciência. Essa afirmativa não deve de modo algum ser considerada como uma insuficiência da psicanálise; é antes uma precisão do problema que ela pretende tratar. Sem essa precisão, corre-se o risco de a psicanálise perder a sua orientação na clínica.

Somente quando se abandonam os referenciais próprios à função realista, quando se abandonam as pretensões de fazer da psicanál ise uma ciência e quando se torna logicamente compatível com o pensamento científico, que a psicanálise pode ser considerada um pensamento e uma clínica do real e o sujeito de fato subvertido. Isso significa que só a partir dos questionamentos operados sobre o campo da psicanálise como um campo ético não reduzido à ciência, como pretendem as ciências humanas, não reduzindo a ciência à ética, como pretende a filosofia, e levando em consideração o sentido do problema, é que

\footnotetext{
7 Como afirma Lacan: "O estatuto do inconsciente, que eu lhes indico tão fragilmente no
} plano ôntico, é ético" (LACAN, 1964/ 1985b, p.37). 
a psicanálise pode tratar as suas questões em função de um pensamento e uma clínica do real.

A conseqüência dessa posição é a subversão do sujei to. E esta posição se situará tanto no princípio de colocação do problema do sujeito quanto em sua relação com a ciência. Se a psicanálise pretende ser compatível logicamente com a ciência, deve, em primeiro lugar, abandonar a pretensão de tratar o seu problema o sujeito - a partir de uma ciência; e, em segundo lugar, desistir de tentar subordinar a ciência a um procedimento que Ihe é exterior. A psicanálise seria desse modo logicamente compatível com a ciência por seguir o sentido do seu problema, tal como faz a ciência, sem pretender ser uma ciência. A pretensão tanto da filosofia, quando pretende se fundamentar em um sujeito, quanto das ciências humanas foram reunidas sob a rubrica da função realista. Mas para ambos, o sujeito, seja el e transcendental, seja ele reduzido a um suposto fato psíquico, pretende ser uma resposta ao problema da ética. Para a psicanálise, essas propostas, por tentarem tratar do problema com conceitos ou direções que não são próprios aos problemas, acabam provocando um resíduo que fica excluído. É justamente isso que a psicanálise chama de sujeito. Em outros termos: enquanto para a filosofia o sujeito é uma resposta, para a psicanálise é ele mesmo quem será colocado em questão: ela articula o efeito dessa aspiração de uma orientação válida para todos.

Mas, ao dizer que trata de um sujeito, a psicanálise não pode deixar também de lado a questão: como tomar uma decisão? "Se não houver falta, não há sujeito" (MILLER, 1998, p.452). Ou seja, enquanto para a filosofia o sujeito é uma resposta, para a psicanálise é a questão. Enquanto para a filosofia é o fim de sua procura, para a psicanálise é o início de seu empreendimento clínico.

É por essa via que se torna possível um encaminhamento positivo à subversão do sujeito. Com efeito, se a psicanálise é logicamente compatível com a atividade científica, e se estas se unem em torno da recusa de se valerem da função realista, ela não ignora que a maneira de colocar a questão já indica o encaminhamento a ser dado.

É na dimensão de valores que aparece o problema de um sujeito: o sujeito é uma interrogação sobre a validade de um valor. Dito de outra maneira: o sujeito só surge quando aquela instância que de algum modo fornecia uma satisfação para o sujeito já não fornece mais. Aquele valor que de certo modo fornecia sentido à existência de alguém perde o seu sentido e a sua possibilidade de ser insubstituível. 0 sujeito então, por ser uma instância que avalia, não pode mais ser colocado como um dado, nem como uma realidade objetiva: daí a impossibilidade de situar esse problema sob a condição de uma objetividade. E como conseqüência desta articulação de pensamento em que não podemos oferecer uma definição operatória - ao tratar de alguém que pensa, não podemos mais 
situá-lo sob uma experiência repetível - , devemos tratá-lo como uma função que avalia. E nesse registro chegamos ao registro da linguagem. Um sujeito só pode julgar a partir do momento em que é afetado pela linguagem. E ser afetado pela linguagem significa perder uma orientação natural. Desse modo, torna-se patente a seguinte questão: um sujeito aparece quando a orientação falha. É por essa razão que a linguagem deve ser colocada, no estudo do que se refere a um psiquismo, como uma matriz principal.

E é por isso que a linguagem irá servir de referência para a psicanálise. E todas as vezes que a psicanálise pretende apresentar algo para fora da linguagem, ela perde a sua orientação. Não por quenão queremos coisas diferentes, mas por perder o sentido de seu problema - ético - a maneira própria de tratálo - a fala e a linguagem, e o universo em que esse problema pode surgir - sem qualidades e infinito. É somente com o abandono do realismo que essa posição é possível. Apenas com o abandono do realismo em epistemologia pode-se chegar à conclusão de Lacan: a de que o pensamento psicanalítico, sua práxis, só pode surgir em um mundo que perdeu as qualidades; afinal de contas, o que éo sujeito do significante senão este sem qualidades, esse vazio que fica entre um ponto identificatório que não Ihe dá consistência e um infinito que não Ihe dá um suporte?

Recebido em 21/ 9/ 2005. Aprovado em 5/ 6/ 2006.

\section{REFERÊNCIAS}

BACHELARD, G. ( 1979) A filosofia do não. São Paulo: Abril. (Coleção Os Pensadores)

(1990) Le Materialisme Rationelle. Paris: PUF.

(1996) A formação do espírito científico. Rio de Janeiro: Contraponto.

BLAN CHÉ, R. (1935) La notion de fait psychique. Paris: Libraire Felix Alcan.

CANGUILHEM, G. (1992) Levivant et son milieu. La conaissancedela vie. Paris: J.Vrin.

CHALMERS, A. F. (1999) 0 que éa ciência afinal. São Paulo: Brasiliense.

JACOB, F. (1983) Lógica da vida. Rio de Janeiro: Graal.

KANT, I. (1980) Crítica da razão pura. São Paulo: Abril Cultural.

LACAN, J. (1953/ 1998) "Função e campo da fala e da linguagem em psicanálise", in: Escritos. Rio de Janeiro: J. Zahar.

(1955-1956/ 1985a) 0 Seminário Livro 3, As psicoses. Rio de Janeiro: J. Zahar.

(1964/ 1985b) 0 Seminário Livro 11, Os quatro concètos fundamentais da psicanálise. Rio de Janeiro: J. Zahar. 
(1966/ 1998) "Do sujeito enfim em questão", in: Escritos. Rio de Janeiro: J. Zahar.

MILLER, J-A. (1998) "O avesso de Lacan”, in: Lacan elucidado. Rio de Janeiro: J. Zahar.

MILNER, J-C. ( 1996) A obra clara: Lacan, a ciência ea filosofia. Rio de Janeiro: J. Zahar.

PASQUINELLI, A. ( 1983) Carnap e o positivismo lógico. Lisboa: Edições 70.

ULLMO, J. ( 1967) 0 pensamento científico moderno. Coimbra: Coimbra Editora.

Roberto Calazans

calazans@ufsj.edu.br 